\title{
Evaluation of Different Fabricated Mountages for Various Cocoon Reeling Parameters of Silkworm, Bombyx mori L.
}

\author{
K. P. Sahana ${ }^{1}$, K. G. Banuprakash ${ }^{1}$, K. S. Vinoda ${ }^{2}$, \\ M. T. Lakshminarayan ${ }^{3}$ and Dronachari Manvi ${ }^{4}$ \\ ${ }^{1}$ Department of Sericulture, College of Agriculture, UAS, GKVK, \\ Bengaluru, Karnataka, India \\ ${ }^{2}$ Department of Sericulture, College of sericulture, UAS-B, Chintamani, \\ Karnataka, India \\ ${ }^{3}$ Department of Agricultural Extension, ${ }^{4}$ Department of Agricultural Engineering, College of \\ Agricultural Engineering, UAS, GKVK, Bengaluru, Karnataka, India \\ *Corresponding author
}

\section{A B S T R A C T}

\section{Keywords}

Self mounting structures,

Mountages and cocoon reeling parameters

\section{Article Info}

Accepted:

12 November 2019

Available Online:

10 December 2019
The study was conducted to evaluate the performance of different fabricated mountages viz., spiral mountage, square mountage and zig-zag mountage in comparison with Thalaghattapura ribbon chandrike, plastic collapsible mountage and bamboo mountage on various cocoon reeling parameters by using two different silkworm hybrids viz., the cross breed (CB) (PM x $\mathrm{CSR}_{2}$ ) and the double hybrid (DH) (Krishnaraja) and data were recorded on various cocoon reeling parameters. The study results revealed that, average filament length (AFL) was significantly longest in square mountage $(890.51 \mathrm{~m})$ and shortest in bamboo mountage $(862.27 \mathrm{~m})$ for $\mathrm{CB}$ and the AFL was found non-significant for DH; non breakable filament length (NBFL) was found non significant in CB and it was significantly longer in spiral mountage $(449.56 \mathrm{~m})$ and shorter in plastic mountage (428.83 $\mathrm{m}$ ) for $\mathrm{DH}$; filament weight was significantly maximum in square mountage and ribbon chandrike $(0.287 \mathrm{~g})$ and it was minimum in plastic mountage $(0.252 \mathrm{~g})$ for $\mathrm{CB}$ and the $\mathrm{DH}$ exhibited non-significant difference for filament weight; raw silk percentage was found non-significant for both $\mathrm{CB}$ and $\mathrm{DH}$; significantly higher denier was found in square mountage (2.90) which was coarser denier and finer denier was found in zig-zag mountage (2.61) for CB and the denier was found non-significant for DH. The spiral, square and zigzag mountages have exhibited good results when compared to bamboo and plastic collapsible mountage.

\section{Introduction}

Mountage is a device for providing the platform for mature silkworms to spin cocoons. Several types of mountages are available at the field, some of which are more popular. Farmers use different locally available materials for fabricating such 
mountages. The earlier studies reveal that the type of material used, design and fabrication of the mountage will decide the quality of the cocoon of silkworm, Bombyx mori L. In addition to support for spinning worms, the mountages should satisfy the requirements like, providing convenient and uniform space with suitable dimension for spinning good sized cocoons, discouraging formation of double cocoons and malformed cocoons, providing ventilation for drying up of the last excreta of the worm prior to spinning, enabling easy mounting and harvesting (Shinde et al., 2012). Narrow space affects ventilation for spinning larvae and results in poor reelability of cocoons, simultaneously more space results in wastage of silk in the form of floss to lay foundation by the silkworm for construction of cocoon (Mathur and Qadri, 2010).

An improper use of mounting structure and lack of care during handling and management of mature silkworms results in formation of defective cocoons accounting to a loss of about 5 to 8 per cent of cocoon yield (Chandrakanth et al., 2004). Thus, the quantity and quality of good cocoons depend largely upon the right selection and proper use of mountages during spinning of cocoons by the matured larvae.

Though several kinds of mountages are available, each one is coupled with its own disadvantages. More popularly used bamboo mountages are costly and cannot be used as self mounting structures due to their heavy size and weight. At present, the available self mounting plastic mountages are best suitable for bivoltine breeds of silkworms that too predominantly in seed cocoon formation. Further, it is difficult to maintain uniformity in shape, size and compactness of the cocoon in the self mounting plastic mountages. The reelers using improved reeling machines offer lesser price for the cocoons harvested from plastic mountages as they experienced that the cocoon shell has more moisture content which reduces the reelability and ultimately affects the raw silk quality. By considering these points the recent study was undertaken to evaluate the cocoon reeling parameters among the newly fabricated self mountages.

\section{Materials and Methods}

The effect of different mountages on cocoon reeling parameters of silkworm, Bombyx mori L. were studied 2017-2018. Well established V-1 (Victory-1) mulberry plants grown in red soil with $90 \times 90 \mathrm{~cm}$ spacing were used for the silkworm rearing. 50 Disease Free Layings (DFLs) of each of young age silkworms of cross breed (CB) (PM X CSR 2 ) and bivoltine double hybrid (DH), Krishnaraja $\left\{\mathrm{FC} 1\left(\mathrm{CSR}_{6}\right.\right.$ $\left.\begin{array}{lllllll}\mathrm{x} & \mathrm{CSR}_{26}\end{array}\right) \mathrm{X} \quad \mathrm{FC} 2 \quad\left(\begin{array}{llll}\mathrm{CSR}_{2} & \mathrm{x} & \mathrm{CSR}_{27}\end{array}\right)$ were procured from Registered Chawki Rearing Centres for each rearing separately and they were reared by following the procedure recommended by Dandin et al., (2003).

\section{Treatment details}

Six different mountages viz., Spiral mountage $\left(\mathrm{T}_{1}\right)$, Square mountage $\left(\mathrm{T}_{2}\right)$ and $\mathrm{Zig}-\mathrm{Zag}$ mountage $\left(T_{3}\right)$ were newly designed and fabricated for the present study. Thalaghattapura Ribbon Chandrike $\left(\mathrm{T}_{4}\right)$, Plastic collapsible mountage $\left(\mathrm{T}_{5}\right)$ (Control 1) and Bamboo chandrike $\left(\mathrm{T}_{6}\right)$ (Control 2) were considered for analysis. Three replications were maintained for all the treatments.

The self mounting structures $\left(\mathrm{T}_{1}-\mathrm{T}_{5}\right)$ were placed over the silkworm rearing bed for a period of one and a half hours when the silkworms were at ripening stage. After one and a half hours, mountages were removed from the rearing bed whereas in $\mathrm{T}_{6}$ manual mounting method i.e., picking of ripened worms and mounting on to the mountages was practiced. The cocoons were harvested from 
each mountage on fifth and seventh day of spinning in $\mathrm{CB}$ and $\mathrm{DH}$, respectively which ensures complete cocoon formation. A sample of 10 cocoons per replication was drawn and stifled in a hot air oven at $80{ }^{\circ} \mathrm{C}$ for four hours. Individual cocoons were cooked in boiling water for four minutes to soften the sericin layer and reeled on an "Epprouvette".

The different cocoon reeling parameters were calculated as follows and they were analysed by using Completely Randomized Design as per Sunder Raj et al., (1972). The mean data of two rearings was considered for the statistical analysis.

Average filament length (m): The average length of silk filament was determined by the number of revolutions recorded which was then converted into meter by the formula

Average filament length $(\mathrm{m})=\mathrm{R} \times 1.125, \mathrm{R}=$ Number of revolution, $1.125=$ Circumference of Epprouvette.

Non-breakable filament length (NBFL) (m): It is the average length of the filament that can be unwound from the cocoon without break.

Non- breakable filament length (NBFL) (m) Total filament length

$$
\text { = -- Number of breaks }
$$

Filament weight (g): The silk filament was removed from the Epprouvette and weighed after conditioning at $70^{\circ} \mathrm{C}$ for four hours and it is expressed in grams.

Raw silk percentage (\%): It is calculated using the formula

Raw silk percentage (\%)

Weight of raw silk reeled

$$
\text { Weight of cocoon* }
$$

For the present study raw silk weight was calculated on fresh cocoon weight basis.

Denier: Denier is the weight in grams of 9000 $\mathrm{m}$ of yarn or filament.

Denier

Weight of filament $(\mathrm{g})$

Length of filament (m)

\section{Results and Discussion}

\section{Average filament length (m)}

The average filament length (AFL) of the silk filament was significantly long in $\mathrm{T}_{2}(890.51$ $\mathrm{m})$, which was on par with $\mathrm{T}_{1}(885.5 \mathrm{~m}), \mathrm{T}_{3}$ $(883.70 \mathrm{~m}), \quad \mathrm{T}_{4}(877.65 \mathrm{~m})$ and it was significantly shorter in both the controls (862.28 $\mathrm{m}$ in both $\mathrm{T}_{6}$, the Control 2 and $862.51 \mathrm{~m}$ in $\mathrm{T}_{5}$ the Control 1 for CB (Table 1; Fig. 1). But, the AFL was found non significant for the DH cocoons harvested from different mountages. The cocoon filament measured longest $(1181.68 \mathrm{~m})$ in $\mathrm{T}_{6}$ (Control 2 ) and it was shortest $(1102.91 \mathrm{~m})$ in $\mathrm{T}_{4}$ (Table 2; Fig. 1).

The AFL is longer in bivoltine than the multivoltine and the $\mathrm{CB}$ and the same trend has been observed in the present investigation. Sharanya kumar Gowda (2014) also recorded 1249.20 $\mathrm{m}$ of AFL in DH cocoons and 989.20 $\mathrm{m}$ in $\mathrm{CB}$, also the results fall in line with the findings of Babulal et al., (2005), who recorded longer filament length in bivoltine hybrids than cross breeds. Similar observations were also made by several earlier studies viz., the studies conducted to compare the performance of bivoltine hybrids on different mountages evidenced shorter AFL in the cocoons harvested from plastic collapsible mountages (Shinde et al., 2012), which is also observed in the present investigation. Further, the significant difference in AFL for $\mathrm{CB}$ 
between new self mounting structures and both the controls signifies the suitability of self mounting frames in rearing $\mathrm{CB}$ silkworms. Probably better aeration provided on self mounting structures have encouraged the larvae to spin more efficiently and the space maintained was also convenient for the larvae to spin quality silk.

\section{Non-breakable filament length}

The non-breakable filament length (NBFL) showed contrary results with respect to the breeds when used different cocooning structures. The NBFL was found non significant in $\mathrm{CB}$ that was showed significant difference in the DH. The longest NBFL was recorded $\mathrm{T}_{1}(449.56 \mathrm{~m})$ on par with $\mathrm{T}_{6}$ (Control 2) $(441.28 \mathrm{~m})$, followed by $\mathrm{T}_{2}$ $(436.10 \mathrm{~m}), \mathrm{T}_{4}(434.75 \mathrm{~m}), \mathrm{T}_{3}(430.27 \mathrm{~m})$ while it was shortest in $\mathrm{T}_{5}$ (Control 1) (428.83 m) (Table 1 and Fig. 2). For the cross breed, relatively longer NBFL was observed in $T_{1}$ $(322.50 \mathrm{~m})$ and it was shortest in $\mathrm{T}_{5}$ (Control 1) $(305.11 \mathrm{~m})$ (Table 2 and Fig. 2).

The on par results of spiral and bamboo mountage with respect to the NBFL indicate that the absence of bamboo mat while fabricating the mountage does not make any difference in the quality of cocoon in terms of
NBFL. The structure of cocooning frame plays a vital role in obtaining quality raw silk (Shillin Sangappa et al., 2010), which is evidenced by the present investigation also.

\section{Filament weight (g)}

The cocoon filament weighed significantly heavier in $\mathrm{T}_{2}$ and $\mathrm{T}_{4}(0.287 \mathrm{~g})$ on par with $\mathrm{T}_{1}$ $(0.276 \mathrm{~g})$, followed by $\mathrm{T}_{6}(0.260 \mathrm{~g})$ (Control 2) $(0.260 \mathrm{~g}), \mathrm{T}_{3}(0.257 \mathrm{~g})$ and lighter in $\mathrm{T}_{5}$ (Control 1) (0.252 g) for CB (Table 1 and Fig. 3 ). But in case of DH there was no significant difference among different mountages where $\mathrm{T}_{2}(0.365 \mathrm{~m})$ recorded relatively maximum weight of the filament followed by $\mathrm{T}_{6}$ (Control 2) $(0.364 \mathrm{~m}), \mathrm{T}_{1}(0.365 \mathrm{~g}), \mathrm{T}_{3}(0.361 \mathrm{~g}), \mathrm{T}_{5}$ (Control 1) $(0.357 \mathrm{~g})$ and $\mathrm{T}_{4}(0.353 \mathrm{~g})$ (Table 1 and Fig. 3).

The variation in the weight of silk filament was perhaps due to varied length of the silk filament among the two silkworm hybrids. The filament weighed significantly lighter when plastic mountage was used to mount the ripened worms. This perhaps also would be due to the non absorbance nature of raw material used to fabricate the mountage, which hardly removes the moisture from the silk filament.

Table.1 Effect of different mountages on various reeling parameters of the cross breed, PM x $\mathrm{CSR}_{2}$

\begin{tabular}{|c|c|c|c|c|c|}
\hline Particulars & AFL (m) & NBFL (m) & $\begin{array}{c}\text { Cocoon filament } \\
\text { weight }(\mathbf{g})\end{array}$ & Raw Silk (\%) & Denier \\
\hline T1 & 885.58 & 322.50 & 0.276 & 14.85 & 2.80 \\
\hline T2 & 890.51 & 313.80 & 0.287 & 16.40 & 2.90 \\
\hline T3 & 883.70 & 309.71 & 0.257 & 15.26 & 2.61 \\
\hline T4 & 877.65 & 311.92 & 0.287 & 16.38 & 2.71 \\
\hline T5 & 862.51 & 305.11 & 0.252 & 15.84 & 2.62 \\
\hline T6 & 862.27 & 312.46 & 0.260 & 14.71 & 2.70 \\
\hline F-test & $* *$ & NS & $* *$ & NS & $* *$ \\
\hline SE. m \pm & 5.086 & 3.814 & 0.003 & 0.699 & 0.032 \\
\hline CD & 21.969 & 16.474 & 0.014 & 3.020 & 0.139 \\
\hline
\end{tabular}

** significant at $1 \%$; NS- Non significant 
Table.2 Effect of different mountages on various cocoon reeling parameters of the Double Hybrid, Krishnaraja

\begin{tabular}{|c|c|c|c|c|c|}
\hline Particulars & AFL (m) & $\begin{array}{c}\text { NBFL } \\
(\mathbf{m})\end{array}$ & $\begin{array}{c}\text { Cocoon Filament } \\
\text { weight }(\mathbf{g})\end{array}$ & $\begin{array}{c}\text { Raw Silk } \\
(\mathbf{\%})\end{array}$ & Denier \\
\hline T1 & 1155.65 & 449.56 & 0.363 & 18.81 & 2.83 \\
\hline T2 & 1146.91 & 436.10 & 0.365 & 18.28 & 2.86 \\
\hline T3 & 1149.13 & 430.27 & 0.361 & 19.60 & 2.87 \\
\hline T4 & 1102.91 & 434.75 & 0.353 & 19.11 & 2.88 \\
\hline T5 & 1146.35 & 428.83 & 0.357 & 18.68 & 2.81 \\
\hline T6 & 1181.68 & 441.28 & 0.364 & 17.55 & 2.78 \\
\hline F-test & NS & $*$ & NS & NS & NS \\
\hline SE. $\mathbf{m} \pm$ & 19.853 & 4.115 & 0.005 & 0.691 & 0.043 \\
\hline CD & 85.761 & 12.681 & 0.020 & 2.985 & 0.186 \\
\hline
\end{tabular}

significant at 5\%; NS- Non Significant

Fig.1 Average Filament length for PM x CSR 2 (CB) and Krishnaraja (DH) as influenced by different mountages

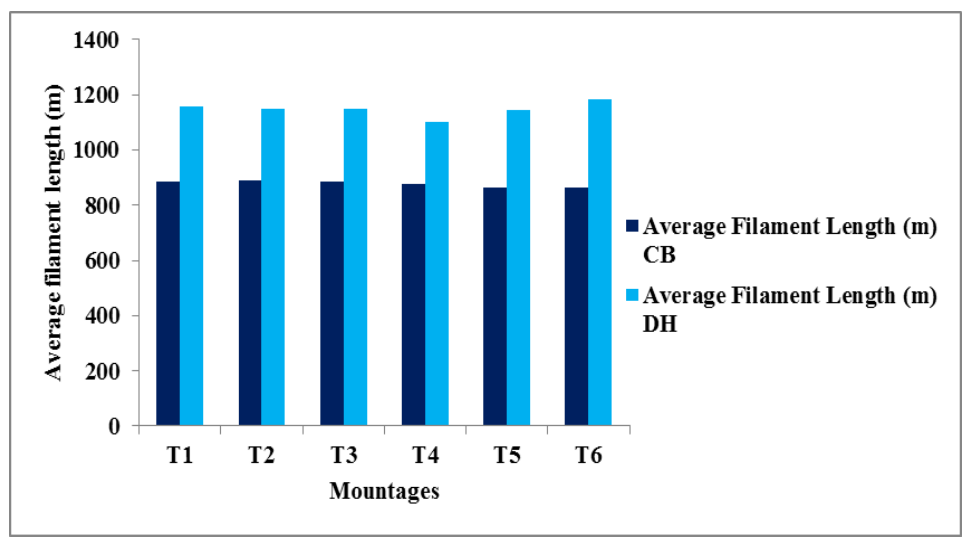

Fig.2 Non breakable filament length (NBFL) for PM x CSR $2(C B)$ and Krishnaraja (DH) as influenced by different mountages

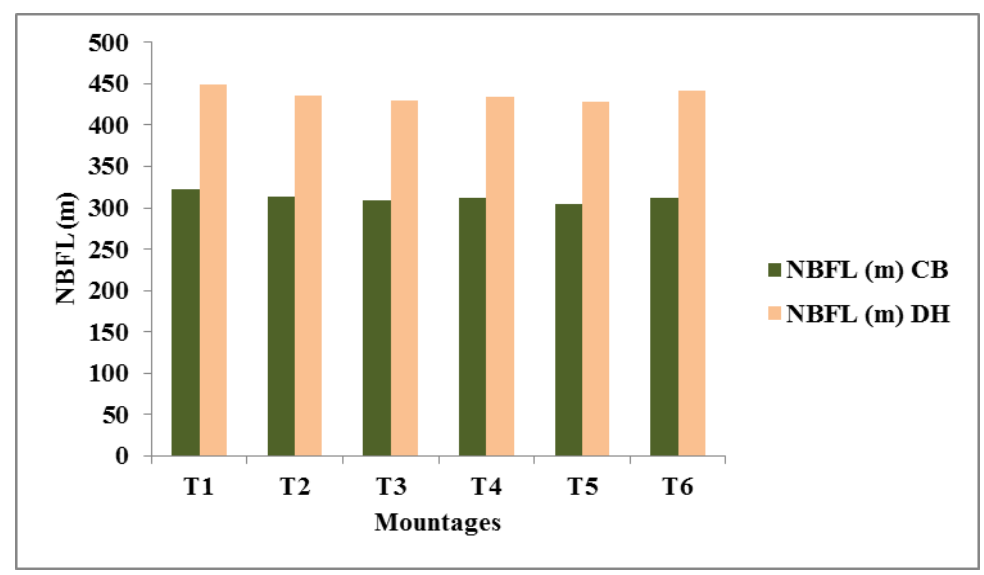


Fig.3 Filament weight for PM x $\mathrm{CSR}_{2}(\mathrm{CB})$ and Krishnaraja (DH) as influenced by different mountages

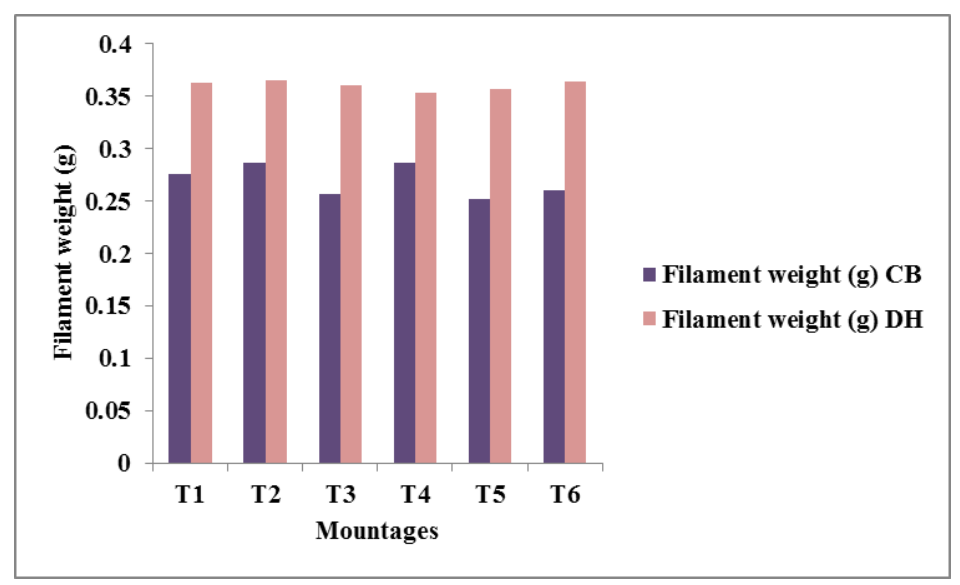

Fig.4 Raw silk percentage for PM x CSR $2(C B)$ and Krishnaraja (DH) as influenced by different mountages

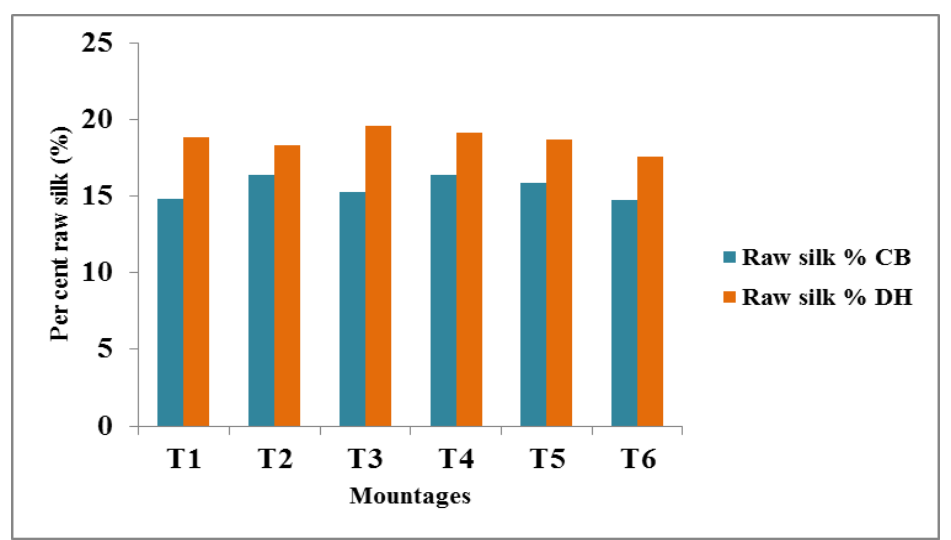

Fig.5 Denier for PM x CSR 2 (CB) and Krishnaraja (DH) as influenced by different mountages

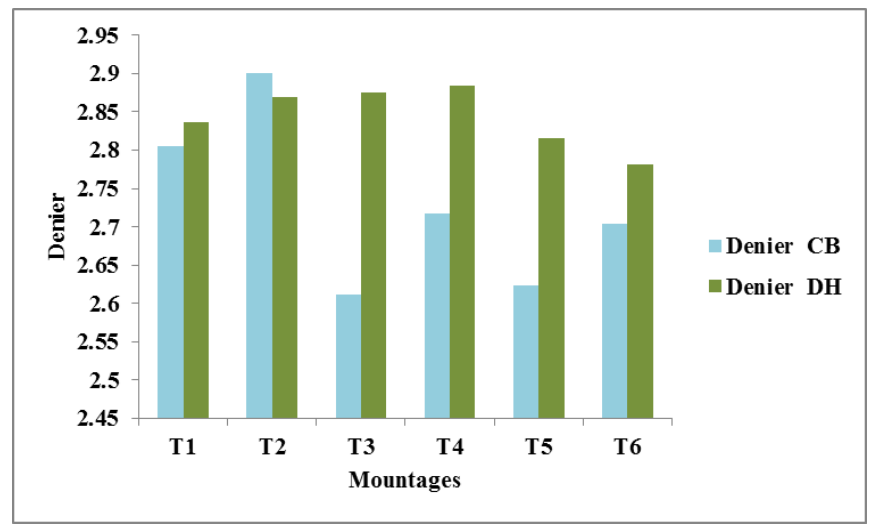




\section{Raw silk percentage (\%)}

The raw silk percentage was found non significant in both $\mathrm{CB}$ and $\mathrm{DH}$. However, maximum raw silk percentage was found in $\mathrm{T}_{2}$ $(16.40 \%)$ followed by $\mathrm{T}_{4}(16.38 \%), \mathrm{T}_{5}$ (Control 1) (15.84 \%), $\mathrm{T}_{3}(15.26 \%), \mathrm{T}_{1}(14.85$ $\%)$ and minimum percentage was with $\mathrm{T}_{6}$ (Control 2) (14.71\%) for CB (Table 1 and Fig. 4). For $\mathrm{DH}_{3} \mathrm{~T}_{3}(19.60 \%)$ showed maximum raw silk percentage followed by $\mathrm{T}_{4}$ (19.11\%), $\mathrm{T}_{1}(18.81 \%), \mathrm{T}_{5}$ (Control 1) (18.68\%), $\mathrm{T}_{2}(18.28 \%)$ and minimum percentage was with $\mathrm{T}_{6}$ (Control 2) (17.5\%) (Table 2 and Fig. 4).

The lower raw silk percentage in the manually mounting cocooning frame compared to self mounting structures was perhaps due to heavier pupa because the total cocoon weight is considered while computing the per cent rawsilk recovered from the cocoon. However, this observation may further be confirmed.

\section{Denier}

The filament denier differed significantly with respect to the two breeds on different mountages. The $\mathrm{T}_{3}$ showed finer denier (2.61) on par with $\mathrm{T}_{5}$ (Control 1) (2.62), $\mathrm{T}_{6}$ (Control 2) (2.70), $T_{4}$ (2.71) and it was heavier in $T_{1}$ (2.80) and $\mathrm{T}_{2}$ (2.90) for CB (Table 1; Fig. 5). For DH, the denier did not show significant difference. Relatively finer was the denier in $\mathrm{T}_{6}$ (Control 2) (2.78), followed by $\mathrm{T}_{5}$ (Control 1) (2.81), $\mathrm{T}_{1}$ (2.83), $\mathrm{T}_{2}(2.86), \mathrm{T}_{3}(2.87)$ and $\mathrm{T}_{4}$ (2.88) (Table 2; Fig. 5).

Denier is a computed parameter, which considers both length and weight of the reeled filament. Though finer denier is preferred in sericulture industry, the cocoons with less NBFL is more valued than longer filament length. In the present investigation, the zig-zag and plastic mountages recorded low values for denier that is in line with the observation recorded by Shinde et al., (2012), where they reported 2.1 denier for plastic mountage.

The objective of sericulture is the production of large quantity of good cocoons which in turn result in production of good quality raw silk. This cannot be obtained only by the improvement of mulberry cultivation and silkworm rearing, but also by improving the method of mounting and mountages used (Singh et al., 1994). Therefore, the present study was conducted to study the different reeling parameters of cocoons obtained from new mountages in comparison with the controls and showed that, the new mountages were exhibited better results when compared to bamboo and plastic mountages. However, subsequent studies are needed to verify as which of these new mountages would be the best mountage to release into farmers' field.

\section{References}

Babulal, Siddiqui,A.A., Khatri,R.K. and Sharma, A.K. Bivoltine cocoon production - an analysis of yield gaps and constraints. Indian silk. 2005; 44(4):13-15.

Chandrakanth, K.S., SrinivasaBabu, G.K., Dandin, S.B., Mathur, V.B.and Mahadevamurthy, T.S. Development of improved mountages. Indian Silk. 2004, 43 (5): 07-12.

Dandin, S.B., Jayaswal, J. and Giridhar, K. Handbook of Sericulture Technologies. CSB, Bangalore, 2003, 287.

Mathur, V.B. and Qadri, S.M.H. Manual on Mountages, Mounting and Harvesting Technology for Quality Cocoon Production. C.S.R. and T.I, Mysore. 2010, 23.

Sharanyakumar Gowda, Y.K. The performance of double hybrids of silkworm, Bombyx mori L. in Central Dry Zone of Karnataka. M. Sc. (Seri.) Thesis, UAS, Bangalore.2014, 92. 
Shillin Sangappa, Bhanuprakash Raj, Srinivasa $G$ and Dandin, S.B. Impact of different types of mountages on raw silk production and quality. Journal of Silk Science Technology of Japan. 2010; 18: 15-19.

Shinde, K.S., Avhad, S.B., Jamdar, S. V. and Hiware, C.J. Comparative studies on the performance of mountages on cocoon quality of Bombyx mori L. Trends in Life Science.2012; 1: 8-11.

Singh, G.B., Rajan, R.K., Inokuchi, T.,
Himantharaj, M.T., Meenal, A. and Datta, R.K. Studies on the use of plastic bottle brush mountages for silkworm mounting and its effect on cocoon characters and reelability. Indian Journal of Sericulture. 1994; 33(1): 95-97.

Sundar Raj, N., NagarajuS., Venkataramu, M.N. and Jagannath, M.K. Design and analysis of Field Experiments. Directorate of Research, UAS, Bangalore. 1972, 139.

\section{How to cite this article:}

Sahana, K. P., K. G. Banuprakash, K. S. Vinoda, M. T. Lakshminarayan and Dronachari Manvi. 2019. Evaluation of Different Fabricated Mountages for Various Cocoon Reeling Parameters of Silkworm, Bombyx mori L. Int.J.Curr.Microbiol.App.Sci. 8(12): 1629-1636. doi: https://doi.org/10.20546/ijcmas.2019.812.196 